Cómo citar este artículo en MLA: Blanco Cortina, D. "El encanto de la duda en Doce hombres en pugna”. Escritos 27.58 (2019): 1-25. doi: http://dx.doi.org/10.18566/escr.v27n58.a01

Fecha de recepción: 01.06 .2018

Fecha de aceptación: 14.01.2019

\title{
El encanto de la duda en Doce hombres en pugna
}

\section{Enchantment of Doubt in Twelve Angry Men \\ O encantamento da dúvida em doze homens e uma sentença}

\author{
David Blanco Cortina ${ }^{1}$
}

\section{RESUMEN}

El presente artículo toma como excusa un análisis de la película Doce hombres en punga para introducir, con ánimo propedéutico, tres cuestiones: i) el núcleo conceptual de la retórica, ii) el razonamiento abductivo, y iii) la relación entre argumentación y emociones. Sobre la primera cuestión se proponen tres discusiones: el puesto del logos, el pathos y el ethos en la retórica, la relación entre retórica y dialéctica, y la idea de persuasión. Sobre la segunda se exponen las tres dimensiones de la abducción para una compresión adecuada: la inferencial, la metodológica y la intuitiva. La tercera cuestión queda perfilada con algunas sugerencias sobre el papel de las emociones en la argumentación y la exigencia de una ética mínima para el ejercicio retórico. Esas tres cuestiones no son neutras y suponen profundas discusiones.

1 Magíster en Derecho y candidato a magister en Filosofía por la Universidad Nacional de Colombia. Integrante del grupo de investigación Derecho Constitucional y Derechos Humanos, Universidad Nacional de Colombia. Correo electrónico: djblancoc@unal.edu.co 


\title{
Palabras clave:
}

Doce hombres en pugna, Retórica, Dialéctica, Abducción, Emoción, Argumentación.

\begin{abstract}
The article proposes an analysis of the film Twelve Angry Men to address, with a propaedeutic spirit, three issues: i) the conceptual core of rhetoric, ii) abductive reasoning, and iii) the relation between argumentation and emotions. Regarding the first issue, three points are considered: the place of logos, pathos and ethos within rhetoric; the relation between rhetoric and dialectics; and the idea of persuasion. Regarding the second one, the three dimensions of abduction are presented, that is, the inferential, methodological and intuitive ones. Finally, the third issue is outlined with some suggestions concerning the role of emotions within argumentation and the requirement of minimum ethical standards for rhetorical practice. The three issues are not neutral and require deep considerations.
\end{abstract}

\section{Key Words:}

Twelve Angry Men, Rhetoric, Dialectics, Abduction, Emotion, Argumentation.

\section{RESUMO}

Esse artigo propõe uma analise do film Doze Homens e uma Sentença para introduzir propedêuticamente três questões: i) o núcleo conceitual da retórica, ii) o raciocínio abdutivo e iii) a relação entre argumentação e emoções. Sobre a primeira questão se propõem três discussões: o lugar do logos, o pathos e o ethos na retórica, a relação entre retórica e dialética e a ideia da persuasão. A respeito da segunda se expõem três dimensões da abdução para uma compreensão adequada: a dimensão inferencial, a metodológica e a intuitiva. A terceira questão se trata a partir de algumas sugestões sobre o papel das emoções na argumentação e a exigência de uma ética mínima para o exercício retórico. Essas três questões não são neutras e supõem profundas discussões.

\section{Palabras-chave:}

Doze Homens e uma Sentença, retórica, dialética, abdução, emoção, argumentação. 
"El poder de descubrir y hacer valer para cada cosa lo que actúa e impresiona, esa fuerza que Aristóteles llama "retórica", es al mismo tiempo la esencia del lenguaje: este, lo mismo que la retórica, tiene una relación mínima con lo verdadero, con la esencia de las cosas; el lenguaje no quiere instruir sino transmitir (übertragen) a otro una emoción y una aprehensión subjetiva".

Nietzsche [1872]

\section{Introducción}

T a primera imagen que vemos al comienzo de Twelve Angry $\mathrm{Men}^{2}$ es la escalera de entrada a un lugar sagrado en Occidente: las salas de juzgados Jy tribunales. Un mensaje recibe al visitante: "[t]he true administration of justice is the firmest pillar of good government". Esta frase descansa sobre columnas corintias que se elevan imponentes. Sin esas columnas, pareciera decirnos la cámara del director Sidney Lumet, todo el edificio se vendría abajo por la densidad de esa idea: la justicia es el pilar más firme de un buen gobierno. Pero además de aquellas columnas de granito, para hacer justicia es necesaria la convicción de doce hombres hechos, no de piedra, sino de algo más maleable: emociones que atraviesan los huesos y pulsiones que hacen palpitar la carne.

El espectador aprecia la majestuosidad del lugar: el templo en cuyo interior reposa la justicia de los hombres como un sucedáneo de la justicia divina. Este primer cuadro, con la potencia de su mensaje, parece darle la razón a Nietzsche: el lenguaje -o la retórica que es su esencia- no instruye, sino que transmite una emoción y una aprehensión subjetiva ("Escritos" 91), pero lo hace a través de un mecanismo que se ha pretendido del todo racional, la argumentación. No obstante, la argumentación retórica en la que pathos, ethos y logos se articulan, para develar aquello que actúa e impresiona de cada cosa, va más allá de la lógica formal, y en ella la razón solo es un elemento entre otros. La película permite apreciar esta particularidad de la argumentación retórica, sobre todo en el ámbito judicial.

2 Esta película de 1957 se conoce en Colombia como Doce hombres en punga, pero también fue traducida en otros países de habla hispana como Doce hombres sin piedad. 
Doce hombres deben decidir la inocencia o culpabilidad de un joven acusado de homicidio, pero no cualquier homicidio. Es la muerte de su padre. Nada menos y nada más que un parricidio, un crimen repudiado por los hombres de todas las épocas. El juez descarga sobre ellos toda la responsabilidad de la decisión y les traza el camino: deben separar los hechos de la fantasía; un hombre ha muerto y la vida de otro está en sus manos; si el veredicto es culpable, la condena es la muerte, pero si tienen una duda razonable, deben declararlo inocente. En cualquier caso, la decisión debe ser unánime.

Esas palabras sintetizan la trama del guion de Reginald Rose, ${ }^{3}$ cuyo desarrollo posterior se concentra en el interior de una sala con cuatro ventanas, un baño, un tanque de agua a medio llenar, dos mesas cuadradas que juntas forman una sola rectangular, rodeada de doce sillas de madera y un ventilador que se rehúsa a funcionar. El calor se instala en la sala después de que el encargado, desde afuera, le pone cerrojo a la única puerta, como anunciando que están condenados a decidir y no podrán abandonar su labor hasta que la decisión se pegue a su piel como el sudor que los agobia.

La controversia comienza en medio de ese calor que "[...] lo aplasta todo, tiraniza el mundo, corroe lo salvable y despierta solo las iras, los rencores, las envidias, los odios más infernales" (Padura, 13). Los jurados están sentados alrededor de la mesa. Once de ellos dan por descontado que el acusado es culpable y la única pregunta que parece inquietarlos es: ¿cómo puede hacer tanto calor?

La deliberación que se va desgranando durante la hora y media que demora el filme me permitirá introducir tres aspectos característicos de la argumentación judicial: retórica, abducción y emoción. Cada uno de los jurados representa un argumento y un sentimiento diferente que justifica el contenido de la decisión final, que puede asumirse como una representación prototípica de los elementos que inciden en el juez a la hora de resolver un caso. La discusión de los jurados resalta el papel fundante de la pregunta, de la duda, en la justificación dialógica de la decisión judicial. Por ahí empezaré el análisis.

3 Cabe destacar que este guion fue elaborado, en principio, para televisión y luego adaptado para cine y teatro. 


\section{En el principio era la duda y la duda era Dios}

Mientras van acomodándose en la sala, cada jurado exhibe sus prejuicios, sus convicciones y sus impresiones del caso. El jurado número 8 -Henry Fondase mantiene en pie mirando a través de la ventana el paisaje de edificios que acorralan la justicia en las urbes modernas, hasta que el número 1, presidente del jurado, interrumpe sus cavilaciones al convocarlo para que ocupe su lugar en la mesa. Una vez ubicados en sus puestos, todos votan a favor de la silla eléctrica para el acusado, excepto el jurado 8 . Ante este disenso inesperado que rompe la unanimidad virtual de la decisión, el jurado 10 le pregunta “iqué quiere?”.

La respuesta del jurado 8 es simple: "solo quiere hablarlo, discutirlo". Enseguida, el jurado 7 interviene para decir que ni aún en el evento de que lo hablaran 100 veces, cambiaría su opinión sobre la culpabilidad del acusado. El jurado 8 reitera que no pretende hacerlo cambiar de opinión, solo quiere hablarlo. Se trata de la vida de alguien y considera que lo mínimo es que lo hablen, que le dediquen unas pocas palabras. No está seguro de si es inocente o culpable, no sabe si creer o no en la teoría del caso presentada por la defensa, pero cree que deben discutirlo antes de mandar a la silla eléctrica a un muchacho maltratado por la vida durante 18 años.

Entonces, ¿quién debe convencer a quién? ¿El jurado 8 a los demás o los 11 restantes al jurado capaz de dudar? En realidad, lo que hace el jurado díscolo es extenderle una invitación a los demás: los invita a negociar la distancia que los separa, negociar su duda por la vía de los argumentos. Esa invitación constituye el núcleo de la retórica.

\section{Pathos, logos y ethos}

Desde Aristóteles se ha puesto el énfasis en la persuasión para definir la retórica: "Sea la retórica la facultad de considerar en cada caso lo que cabe para persuadir" (Aristóteles, 1355b25). Se trata, entonces, de un arte sobre los medios necesarios para persuadir en el campo de la razón práctica, es decir, de la acción y las ciencias sociales o prácticas. ${ }^{4}$ El Estagirita identificó tres medios

4 La razón práctica, por oposición a la teórica, se refiere a la cuestión sobre qué hacer, qué cursos de acción tomar frente a determinada situación problemática. Así, la razón 
de la argumentación retórica, según su punto de partida, pues unos "residen en el carácter del que habla [ethos], otros en poner en cierta disposición al oyente [pathos], otros en el mismo discurso, por lo que demuestra o parece demostrar [logos]" (Aristóteles, 1356a).

La película nos muestra varios argumentos de cada una de estas clases. Por ejemplo, el jurado 10 sostiene que el acusado no es un típico WASP, ${ }^{5}$ sino que se trata de un muchacho pobre, que creció en un barrio marginal y con una familia disfuncional; por lo tanto, su historia no sería para nada creíble. Afirma que ha vivido entre ellos y que los conoce tan bien como para saber que no hay que creerles nada. ${ }^{6}$ En su siguiente intervención, para mostrar la falsedad de la historia del acusado, recurre al testimonio de una vecina que afirma haber visto el homicidio, es decir, una mujer con las mismas características socioculturales del acusado. Ante ello, el perspicaz jurado 8 le replica sobre por qué ha de creérsele a la mujer, y no al chico, si ambos pertenecen a la misma 'clase de gente', que el jurado 10 dice conocer muy bien para saber que no hay que creerles. Este argumento cuestiona el ethos del jurado 10, cuyo carácter evidencia una inconsistencia al aplicar distintos raseros a 'especies de una misma clase?

Por otra parte, el jurado 3 señala que no tiene ningún sentimiento personal en juego, que sabe que el acusado solo tiene 18 años, pero en todo caso debe pagar por lo que hizo, y respalda su posición con el testimonio de un anciano que vive debajo del apartamento en el que sucedieron los hechos. El testigo dijo haber visto al acusado salir corriendo después de una acalorada discusión con su padre, en la que aquel gritó: "te voy a matar". Momentos más tarde se

práctica se preocupa por la acción justificada, mientras la teórica se concentra en la justificación racional de aseveraciones que informan o describen sobre un estado real de cosas. El lugar común indica que la retórica solo participa de la razón práctica y no juega ningún rol en ejercicios de razón teórica, dominada, casi por completo, por la lógica. Ya veremos cómo esta convención puede ser reconsiderada.

5 Blanco, anglosajón y protestante, por sus siglas en inglés White, anglo-saxon and protestant.

6 El entimema deja implícito una premisa que pudiera formularse así: "el testimonio de cualquier persona pobre, habitante de un barrio marginal y procedente de una familia disfuncional carece de credibilidad". 
descubrió el cadáver del padre, con una puñalada en el pecho. Este argumento se construye sobre el logos, sobre la razón que sigue con atención lo que los hechos parecen demostrar. Este argumento responde a la consigna del hombre de la toga: dividir los hechos y aislar la fantasía.

En un momento especial del drama, el jurado 4 desarrolla un razonamiento a partir de la singular navaja con la que la víctima había sido apuñalada y se presume que el acusado la compró horas antes del homicidio. De acuerdo con la fiscalía y la mayoría de los jurados, la navaja era única, peculiar y muy difícil de conseguir. Pues bien, en una estrategia argumentativa que apunta al pathos del auditorio, el jurado 8 pide que traigan la navaja para analizarla. Luego de un repaso concienzudo de los hechos, el jurado 4 despliega la navaja y la clava en la mesa, para rematar diciéndole al 8: "mire esta navaja. Es una navaja muy inusual. Nunca vi una igual. Ni tampoco el dueño de la tienda que se la vendió al chico. ¿Nos está pidiendo, acaso, que aceptemos una increíble coincidencia?". El jurado 8 afirma que es posible que alguien haya comprado una navaja similar para apuñalar a la víctima, y que el acusado haya perdido la suya, como sostuvo la defensa. El jurado 3 replica con agresividad que eso no es posible.

En el entretanto, un silencio denso ocupa la sala y la cámara nos muestra en primer plano la navaja clavada en la mesa, mientras el jurado 8 se levanta y de uno de los bolsillos de su traje extrae una navaja idéntica y la clava al lado del arma homicida. La mudez se rompe con la algarabía del auditorio que siente deshacer una de sus más íntimas convicciones, pero se niega a aceptarlo: buscan nuevas razones para blindar el veredicto inicial, ante cualquier duda.

Pero la duda, aunque el auditorio se resista, ha empezado a horadar la muralla de sus certezas, y la invitación a negociar la distancia se renueva. El jurado 8 propone una nueva votación sin contar el suyo propio. Si los 11 votan al unísono a favor de la condena, el disidente se rendiría y se adhería a la decisión. Pero si uno solo cambia de parecer, la discusión continuaría. La película pudiese terminar allí, si cada uno hubiera escrito en un papel, en secreto: 'culpable'. No obstante, para sorpresa de todos, el presidente del jurado lee not guilty. Uno de los jurados se ha dejado seducir por la duda, dispuesto a negociar la distancia entre la silla eléctrica y una segunda oportunidad sobre la tierra para el acusado. 


\section{Retórica y dialéctica}

Un aspecto crucial que enseña este filme es la relación complementaria entre dialéctica y retórica. Ya Aristóteles lo había señalado al comienzo de su Retórica: "[...] la retórica es correlativa de la dialéctica" (1354a); y las teorías de la argumentación contemporáneas se esfuerzan por encontrar la ruta para evidenciar dicha correlación. En tal sentido, Van Eemeren señala que:

Cuando la argumentación se considera, en primer lugar, como destinada a resolver una diferencia de opinión, la perspectiva que se tiene es sobre todo dialéctica, y cuando la argumentación se ve, en primer lugar, como un objetivo para alcanzar un acuerdo con la aceptación del punto de vista acordado por el público, la perspectiva que se tiene es, sobre todo, retórica. [...] la dialéctica se asocia, en primer lugar, con la evaluación e opiniones al tratar de resolver las diferencias de opinión sobre el fondo, y la retórica, con la creación de consenso, tratando de resolver las diferencias de opinión de acuerdo con las partes interesadas (Maniobras 153).

La dialéctica puede ser entendida como un intercambio de razones en el contexto de un diálogo reglado -aunque sea en grado mínimo-, en el que se intenta resolver una diferencia de opinión entre dos intervinientes: un interlocutor y su oponente (Van Eemeren y Grootendorst). Ahora, cuando en la discusión intervienen más de dos personas, como en el filme, ya no estaríamos ante un diálogo o una perspectiva dialéctica, sino frente a un polílogo -poli, muchos- o la dimensión polilógica de la argumentación en la deliberación pública (Lewiński).

La deliberación en Doce hombres en pugna resalta esta relación simbiótica entre dialéctica y retórica en la medida que la discusión crítica se resuelve por dos vías: la razonabilidad de las posturas de los miembros del jurado y el consenso que se produce por la fuerza persuasiva de los argumentos, todos ellos entimemáticos. ${ }^{7}$ Lo que descubre la película es que, en ningún evento,

7 Un entimema es un argumento con eficiencia retórica que presupone un tópico o lugar común no explícito en el esquema argumentativo, que garantiza la plausibilidad o garantía de la inferencia que se propone en el curso de un intercambio de razones (Vega). Muchos de los argumentos planteados por los miembros del jurado responden 
la perspectiva dialéctica o polilógica excluye o anula la dimensión retórica, o viceversa.

Por el contrario, ambas dimensiones de la argumentación se asocian para regular un intercambio de razones, que respeta ciertas reglas de razonabilidad sin renunciar a la eficacia persuasiva del discurso. En el debate que recrea la película, la duda sigue labrando el camino para continuar la discusión entre los 12 jurados, pese al fastidio de algunos que prefieren ir a ver un partido de béisbol o atender sus empresas familiares. Los jurados son a un tiempo interlocutores y auditorio particular para quien despliega su argumentación en pos de persuadir a los demás de que su posición es la correcta.

\section{El imperio retórico y la problematología}

Decíamos antes que en la negociación de las distancias residía el núcleo conceptual de la retórica, la cual ha sido definida por la tradición en términos de persuasión. En esa línea, Perelman indicó que su nueva retórica consistía en el estudio de las técnicas discursivas que permiten provocar o aumentar la adhesión del auditorio a las tesis expuestas para su asentimiento.

Por consiguiente, toda argumentación se desarrolla en función del objetivo principal: persuadir, cuando estamos ante un auditorio particular, o convencer, cuando el auditorio es universal. El maestro de Bruselas puso el énfasis en la argumentación racional como nueva lógica de los valores que gobierna la razón práctica $(\log o s)$ y dejó de lado, sin mayor atención, los otros elementos que hacen parte de la concepción retórica aristotélica.

La nueva retórica de Perelman se habría construido entre dos fronteras filosóficas, lo que Plantin denomina el entredós del imperio retórico (177). La razonabilidad retórica hizo a un lado las emociones, bajo la creencia de que la argumentación desaparece allí donde las pasiones ocupan el papel central. Además, el imperio retórico se rindió frente al avance de la evidencia

a estructuras argumentales de carácter entimemático. Aristóteles llamó entimema al "[...] silogismo de menos premisas y muchas veces menores que la del silogismo primero [deductivo]; pues si alguna de ellas es cosa sabida, no es preciso decirla, porque el propio oyente la pone..." (1357a15). 
científica, ante la cual se asumió que solo cabía la demostración cartesiana. En estos casos, la validez del razonamiento solo podría ser enjuiciada con los criterios de la lógica formal. El imperio retórico entonces, se levantó en un espacio ausente de evidencias y de emociones. ${ }^{8}$

De acuerdo con Plantin, la retórica debe ampliar sus dominios, por una parte, hacia las ciencias exactas en los que reina la evidencia. En este caso, muchas veces la evidencia es insuficiente y el único camino para completar el discurso es la argumentación razonable o retórica. Por otra parte, debe incluir el análisis de las pasiones y emociones como elementos constitutivos de la argumentación. No es acertado, como lo indicó Perelman, que ante la evidencia no se argumenta, y que las pasiones solo desembocan en acciones irracionales.

De esta constatación ha surgido el enfoque problematológico de la retórica. Michel Meyer, discípulo de Perelman, nos propone una definición comprensiva de la retórica que involucra esos elementos olvidados. El profesor de la Universidad Libre de Bruselas nos plantea que: "[...] la retórica esla negociación de la distancia entre individuos a propósito de una cuestión dada" (Principia 26). Esta definición es neutra en tanto que no privilegia ningún elemento de la interacción retórica. El ethos, el pathos y el logos encuentran su lugar en esta negociación por cuanto el enfoque se concentra en el cuestionamiento, el problema o la diferencia problematológica que viene dada por la distancia:

Una retórica centrada en el cuestionamiento deja de privilegiar al orador, al interrogador y al que responde, pues cada uno puede serlo en su oportunidad. En cuanto al logos, tendrá que expresar tanto la interrogatividad como aquello que la resuelve, tanto lo problematológico como lo apocrítico. [...] El enfoque problematológico pone el cuestionamiento en el centro; el hombre que cuestiona está él mismo en cuestión, y lo problemático es justamente el hecho de que lo esté (y forme parte de la cuestión). Las respuestas-soluciones se disipan en provecho de las que ponemos en duda [...] (Principia 88).

8 Asumo aquí que emociones y pasiones son sinónimos, aunque entre estas dos nociones es posible fincar distinciones, si los propósitos teóricos fuesen otros. 
Así se puede explicar el desarrollo de Doce hombres en pugna: una constante puesta en cuestión de cada punto de vista y, por tanto, también de la persona que lo sostiene, en virtud del principio de adherencia, "[...] según el cual soy 'en' lo que digo. Si alguno no está de acuerdo con mis opiniones, no está de acuerdo conmigo, pues en cierto modo es a mí mismo a quien pone en entredicho" (Principia 106). ${ }^{9}$

El jurado 8 pone en cuestión el punto de vista de los 11 jurados restantes y con ello también a cada uno de estos, quienes, a su turno, se esfuerzan por hacer entrar en razón a la oveja descarriada. Es un permanente contrapunteo entre respuestas provisionales y dudas y más dudas. Cada vez que alguien da una respuesta, otro pone en duda su capacidad resolutoria.

Meyer anota que "[u]na respuesta es a la vez problematológica y apocrítica, pero no para la misma persona, por cuanto, resolutoria para uno, suscita cuestiones para alguien distinto: esto explica la escisión entre el ethos y el pathos en el diálogo" (Principia 179). Una escisión que puede devenir en el fracaso de la persuasión. La gracia de la retórica está en impedir este fracaso, pero también en renovar la discusión cuando sea necesario, como se aprecia en el filme. Esa distancia entre ethos y pathos se aviva en cada diálogo de la película, los cuales siempre destacan el carácter agonizante de quien argumenta frente a la emoción de quien escucha, el acecho permanente de la pregunta que pone en cuestión el argumento del otro.

Un ejemplo de ello, lo encontramos en la siguiente escena. Mientras intenta desprenderse del calor y la humedad con el agua del lavabo, el jurado 6 le pregunta al 8: “¿cree que [el acusado] es inocente?”. El 8 responde que no lo

9 Habría que tener cuidado con esta idea y otras planteadas por Meyer en el mismo sentido -como la frontera movediza entre ad rem y ad hominen. Creo que la compresión adecuada del principio de adherencia consiste en aceptar que cuando argumentamos, somos responsables de lo que decimos y aquello que dejamos de decir. En tal sentido, debemos asumir el compromiso heredado de nuestras afirmaciones, las consecuencias de lo que no decimos y el deber de justificar nuestros puntos de vistas cuando se cuestionan o se ponen en duda (Brandon, 2002; Blanco, 2016). El ethos impregna nuestro discurso y nuestros movimientos argumentativos en la discusión, dicen cosas sobre nuestro carácter. Por ello, "soy 'en' lo que digo", sin que la discusión crítica desencamine en una batalla de falacias ad hominen abusivos o directos. 
sabe, pero que es posible. El 6 le replica con toda tranquilidad que, pese a conocerlo tan poco, está seguro de que nunca en su vida el jurado 8 había estado tan equivocado como en esta ocasión al obstinarse en discutir el caso. El 8 , sin aspavientos, le pide que suponga que lo están juzgando a él. El jurado 6 sostiene que él no está acostumbrado a suponer, quien supone es su jefe y él es un simple trabajador, pero promete intentarlo y remata: "suponga que, después de tanto hablarlo, el chico sí apuñaló a su padre" y liberamos al culpable de un crimen atroz. La sola idea estremece al jurado 8. La discusión, de nuevo, se pone en marcha.

\section{¿El fracaso de la persuasión?}

Las respuestas en el ámbito jurídico tienden a ser apocríticas o resolutorias, por cuanto es necesario tomar una decisión que resuelva de forma definitiva el problema planteado. ${ }^{10} \mathrm{El}$ intercambio de razones entre los jurados apunta a esa dirección: llegar a una solución por la vía de argumentos persuasivos o convincentes. Sin embargo, para algunos esta no es la marca distintiva de la retórica. La persuasión es tan excepcional que por tal condición resulta intrascendente ocuparse de ella. Esto significa que persuadirnos mediante la argumentación es un extraño fenómeno. Y, pese al fracaso, seguimos argumentando (Angenot, El discurso social 172).

De allí que la retórica, en cuanto disciplina, no deba preocuparse por los modos de superación de las diferencias, sino que debe poner atención al fracaso de la comunicación, en la imposibilidad de transmitir bien un mensaje, en el desacuerdo y la incomprensión. En el centro de la retórica deben ubicarse los cortes argumentativos, las discordancias lógicas y cortes afectivos. El fracaso

10 Es importante destacar la distinción de Hart tan útil, pero poco recordada, entre definitividad y falibilidad. La primera noción indica que las decisiones judiciales son emitidas por autoridades de cierre, lo cual implica que en deben ser respetada en tanto que son vinculantes y obligatorias para todos. No obstante, ello no significa que siempre dichas decisiones sean correctas y acertadas porque quienes las toman son personas investidas de autoridad que son por naturaleza falibles. De allí que las decisiones judiciales merezcan respeto debido a la institucionalidad y estabilidad del orden jurídico, pero también merecen ser criticadas y evaluadas para destacar sus errores y por esta vía ensanchar la diferencia problematológica (Blanco, 2016). 
de la persuasión se produce por una divergencia de los códigos retóricos y las reglas de la argumentación, es decir, que tiene lugar cuando el régimen de lo argumentable, de lo cognoscible y de lo persuasible no es compartido entre los interlocutores.

La retórica debe ocuparse de ese abismo que se abre en el campo de lo debatible, para mantenerse cerca de los procesos argumentativos reales y no perderse en impostadas normas de persuasión que no tienen lugar en el mundo social. De contera, lo que ocurre en los tribunales de justicia no resultaría un buen indicador de lo que pasa cuando la gente argumenta en la vida social:

[B]ajo el peso de la situación jurídica, la retórica... persiste en considerar como su norma el debate entre personas que comparten una misma racionalidad y $[\ldots]$ cuyas divergencias más ásperas no surgen de una 'sordera' cognitiva, sino del 'malentendido'. En suma, si la retórica quiere observar el mundo social y dar razón de él, en vez de ser esa 'ciencia' idealizada, irónica, contrafáctica y, sobre todo, vanamente normativa de debates bien regulados y elocuencia eficaz, debe abandonar el estudio de los desacuerdos nacidos del incesante intercambio de 'buenas razones' para abocarse al análisis de los malentendidos de la comunicación argumentada y al estudio de las divergencias y contradicciones de las estrategias argumentativas y de las rupturas cognitivas (Angenot, sf 8 ).

Pero ¿tendrá razón Angenot al sugerir que olvidemos la idea de la persuasión como uno de los elementos definicionales de la retórica y adherir, por oposición, a una retórica de malentendidos nacidos de rupturas argumentativas que generan diálogos de sordos? En la película podemos encontrar algunas pistas para responder esta pregunta.

En un principio, fue la duda de uno de los jurados lo que desató la trama del filme y penetró las almas de aquellos que se atrincheraban en las barracas de su verdad. Al final, la duda como un Dios propició el milagro: salvó la vida del acusado. Pero el mecanismo milagroso fue la argumentación que partió del cuestionamiento, del problema hacia la respuesta y nuevas cuestiones. El espíritu de los hombres sin piedad se ablandó en virtud de la duda razonable, que minó con cautela y efectividad la verdad que alimentaba los delirios vengadores. 
Creo que una de las cosas más reveladoras de la película es que si bien la persuasión es difícil, no por ello es excepcional o contrafáctica. Es cierto que no siempre la persuasión produce una convicción en el auditorio, sino que en muchos casos busca poner en cuestión otros puntos de vista, dudar de ellos. Si bien son frecuentes los diálogos de sordos en la esfera pública, no por ello se debe renunciar a la posibilidad de acuerdo y sacrificar la labor de negociar las diferencias a través del discurso, porque la posibilidad de construir alianzas, llegar a acuerdos y actuar en conjunto también son rasgos característicos de nuestra vida social, aunque haya casos en los que la adhesión a una tesis y la acción colectiva se deban a factores diferentes de la persuasión argumentativa. En cualquier evento, la situación en los tribunales no está tan alejada de nuestras prácticas comunicativas cotidianas; como tampoco las divergencias lógicas, que refiere Angenot, son una condena a perpetuidad de nuestra vida social. Quizá por ahí empiezan nuestras diferencias, pero no son o, al menos, no deben ser el punto de llegada. La retórica bien ponderada se encarga de evitar la violencia física y de crear identidades para la confrontación argumentativa. Esta confrontación debe ser el espacio o la oportunidad para que negociemos nuestras diferencias e identidades. De eso se trata, de administrar nuestras distancias:

[L]a retórica opera sobre la identidad y la diferencia entre individuos, y es de esta cuestión que ella trata a través de preguntas particulares, puntuales, que concretizan las distancias. Cuando se negocia aquella a partir de la pregunta, de aquello que está en discusión, estamos en el ad rem (res='cosa', en latín, entonces, la causa, aquello que está en tela de juicio) y cuando se hace a partir de la intersubjetividad de los protagonistas, estamos en el ad hominen, pues nos dirigimos a los hombres, a lo que son, a lo que se cree que son, a lo que se quisiera creer que son o a lo que rehúsan ser. [...] una buena retórica pasa a menudo de un plan a otro, del ad rem al ad hominen... (Meyer, La rhetorique 15-16).

La retórica como disciplina y procedimiento debe atender no solo la multiplicación exponencial de lo problemático, a través del discurso argumentativo, sino también la potencialidad de los acuerdos que muchas veces alcanzamos en distintas esferas del mundo social. Doce hombres en pugna nos muestra que el cuestionamiento y la diferencia problemática son inevitables en el discurso práctico: los cortes de lógica argumentativa están a la 
orden del día; pero asimismo enseña que el acuerdo es posible, por lo menos de forma provisional, para mover a la acción y tomar decisiones.

\section{Abducción}

Las hipótesis o el razonamiento abductivo fueron teorizados por vez primera por Charles Peirce en Lección VII: Pragmatismo y abducción, quien planteó la siguiente estructura para caracterizar su funcionamiento:

- Un hecho C resulta sorprendente;

- pero si A fuera verdadera, C sería un hecho común corriente,

- por tanto, hay razón para sospechar que A es verdadera.

Esta presentación permite abordar varios de los argumentos desarrollados en la película. Por ejemplo, el hecho sorprendente de que el acusado le haya dicho al padre que lo va a matar, se explica por un episodio temporal de efervescencia que lo llevó a utilizar esa expresión para explicitar la intensidad de su molestia. El punto aquí es que el mero uso de dicha expresión no demuestra per se ninguna intención real de causar daño. Esa explicación aligera el hecho que resulta prima facie sorprendente.

La abducción puede comprenderse a partir de la diferencia entre tres dimensiones que confluyen en el acto abductivo: metodológica, inferencial e instintiva (Aguayo, 33-53). La primera se refiere a la posibilidad de elaborar hipótesis explicativas de hechos o fenómenos nuevos, que son susceptibles de ser falseadas. La dimensión inferencial o lógica consiste en la 'debilidad' del nexo que lleva de las premisas a la conclusión, que algunos han considerado inválida y, por tanto, poco digna de consideración (Bonorino, 1993). La conclusión que deriva de la abducción tan solo podría probablemente ser verdadera. La verdad solo alcanza grado de sospecha y la conclusión explota toda su debilidad de forma consciente. Por eso, la respuesta final de los Doce hombres en pugna es la duda razonable.

La abducción no logra el grado demostrativo de las pruebas lógicas o la contrastación empírica. Solamente sirve para poner en cuestión, y bajo el 
manto de la duda, los pensamientos delirantes. Es, pudiéramos decir, la vacuna contra la fanfarria y el remedio contra las verdades únicas y absolutas (Constaín). El ejemplo de Peirce (1970) sobre cómo funciona la inferencia abductiva es el siguiente:

Regla: Todas las semillas de esta bolsa son blancas.

Resultado: Estas semillas son blancas.

Caso: Estas semillas eran de esta bolsa.

Por su parte, la dimensión instintiva o triggering (Aliseda, "Abductive Reasoning" 262) hace referencia al instante en que la mente hala el gatillo para disparar la hipótesis: el alumbramiento espontáneo de una alternativa, el repentismo de la hipótesis. Veamos otras conjeturas en el filme que nos permiten apreciar estas dimensiones de la abducción.

\section{Las abducciones en el debate de los jurados}

Recordemos que la fiscalía fundó su teoría del caso en dos testimonios: un anciano, que vive debajo, y una mujer, que vive en frente del apartamento del acusado. El primero dice haber escuchado un cuerpo caer, que luego se supo era el cadáver del padre, muerto por una puñalada. Segundos antes el hijo le había gritado "te voy a matar" en medio de una agria discusión. La mujer afirma que vio el homicidio a través de las ventanas de los vagones del tren que pasó vacío entre las 12.00 y $12.10 \mathrm{am}$. Los rieles del tren separan los dos apartamentos.

El razonamiento del jurado 8 tiene dos momentos. El primer momento le llamaré el argumento del ruido, y el segundo el de los juegos del lenguaje. Según el jurado 8, si el homicidio ocurrió mientras el tren pasaba entre los apartamentos, es poco probable que el anciano haya escuchado al acusado decir "te voy a matar" y el impacto del cuerpo de la víctima contra el piso. Incluso, en caso de que haya escuchado esas palabras, es poco probable que haya identificado la voz del acusado. Pero aún más, si es cierto que el acusado profirió esa expresión, cuántas veces cualquiera de nosotros no ha expresado lo mismo sin intención real de hacer daño a alguien.

El argumento del ruido responde al modus argumentativo que explicita la dimensión metodológica de la abducción. El hecho sorprendente consiste en que el anciano haya escuchado la discusión y la caída del cuerpo moribundo, 
mientras pasaba el tren. La explicación hipotética indica que el ruido del tren distorsionó la audición del testigo anciano. Si descomponemos por premisas esta argumentación, obtendremos la siguiente estructura simplificada: ${ }^{11}$ i) el ruido generado por el paso del tren es tan atronador que es casi imposible escuchar cualquier otro sonido, hasta que no termina de pasar; ii) el homicidio ocurrió, mientras el tren pasaba en medio de los apartamentos; por consiguiente, iii) es bastante probable que el anciano no haya escuchado la discusión y el rebote del cuerpo contra el suelo, como afirmó. Entonces, ¿por qué rindió testimonio en ese sentido? Otro hecho sorprendente.

Nótese que este argumento no responde ni a un silogismo deductivo ni a un razonamiento inductivo o analógico (Copi y Cohen, 540-543 ). No solo porque su estructura y el orden de las premisas no corresponden a los de una deducción o una inducción, sino porque la fuerza del argumento radica en la razonabilidad o posible probabilidad de la hipótesis con la que concluye. Es decir, la conclusión del argumento no es por necesidad verdadera y tampoco es probable. La hipótesis que se deriva del razonamiento abductivo solo podría probablemente ser verdadera, como señalé antes. Para confirmar dicha hipótesis se debe acudir a otros procedimientos lógicos, a efectos de convertir la mera verosimilitud en verdad de algún grado.

Ante la hipótesis de que el anciano no haya oído lo que dijo, bajo juramento, haber escuchado, ¿cómo se explica, entonces, el testimonio del anciano? ¿Mintió? No parece razonable asumir que el testigo faltó a la verdad. Pero el jurado 8 contesta que aún en el caso de que haya podido escuchar que el acusado le dijo al padre I'm gonna kill you, es mucho más razonable comprender dicha expresión como una forma de desatar su ira, mas no como una prueba de la intención de matar al padre.

El segundo momento, el argumento ${ }^{12}$ "de los juegos del lenguaje", se compone

11 Se deben presuponer varias premisas entimemáticas para completar el razonamiento.

12 He utilizado como equivalentes las nociones de argumentación y razonamiento, pero cabría hacer una distinción. Siguiendo a Walton (1990) podríamos decir que la diferencia radica en el contexto de emisión. Mientras el razonamiento se explícita en solitario, por su naturaleza monológica -el individuo enfrentado consigo mismo-, el argumento se propone en el contexto de un diálogo o intercambio de razones entre un 
de las siguientes premisas: i) es frecuente utilizar la expresión I’m gonna kill you para expresar un intenso disgusto por la situación que genera otra persona, a quien consideramos responsable de esa situación; ii) pero no significa que, en efecto, la mataremos; en consecuencia, iii) el acusado pudo haber utilizado dicha expresión para exteriorizar su disgusto, pero no como la manifestación de su designio de matar al padre.

La película también nos ofrece una escena que ejemplifica la dimensión instintiva de la abducción: el testimonio del anciano que dice haber escuchado una discusión y el sonido del cuerpo al caer, tiene pocas posibilidades de ser cierto, como ya se explicó. Ante ello, los jurados se preguntan qué pudo haber llevado al anciano a un testimonio tal. ¿Cómo explicar esa declaración, si se rechaza la hipótesis de que ha mentido a consciencia? En medio de la perplejidad, la cámara pone al jurado 10 en primer plano y una tímida sonrisa asoma en su rostro cuarteado por los años, de repente suelta un "atención, tal vez...” y a continuación desarrolla toda su explicación sobre por qué el testigo anciano pudo haber dado el testimonio que rindió. De eso se trata el aspecto instintivo de la abducción: de la llegada inesperada de una explicación.

\section{Explicación, justificación y abducción}

La abducción permite captar, al menos, dos procesos distintos. Si se enfatiza la dimensión metodológica e instintiva, entonces podremos escudriñar en la lógica del descubrimiento científico o el cambio de paradigmas (Kuhn, 2013).

interlocutor y su oponente o entre varios que discuten para solventar una diferencia de opinión. La diferencia bajo este criterio puede parecer artificial dado que es posible que uno entre en diálogo consigo mismo y cuestione sus propios puntos vista. Por tanto, un razonamiento se convertiría enseguida en un argumento. Una distinción quizás más interesante es la que plantea Meyer entre razonamiento lógico e inferencia retórica. El primero debe explicitar todas sus premisas para ser verdadero por necesidad, "[...] porque no autoriza ninguna alternativa, ninguna puesta en entredicho", mientras que la conclusión de la segunda remite a lo problemático, a la cuestión en disputa, "[s]e puede atacar el sujeto o predicado de un argumento" (Principia 101), debido a que siempre renueva lo que está en discusión. En todo caso, no considero conveniente naturalizar las nociones. Un razonamiento puede ser tan argumentativo como un silogismo deductivo es un argumento, con alcances y estructura diferentes. Fijar una frontera solo sirve para efectos didácticos, pero se derrumba cuando se escarba más a fondo. 
Por el contrario, si se repara más en el aspecto lógico o inferencial podremos ver la estructura de nuestras conjeturas interpretativas y el respaldo argumental que requieren. La diferencia es sutil y el enfoque depende del objetivo del análisis. Así, Aliseda se detiene en el estudio de la abducción para señalar que:

En general se considera el papel de la abducción como el mecanismo para generar las explicaciones de las creencias a incorporar, proceso necesario de acuerdo con el enfoque fundamentalista. Nuestro argumento con respecto a esta conexión es aún más fuerte: el razonamiento abductivo es una forma de cambio epistémico por medio del cual puede modelarse la incorporación de nuevas creencias. Aunque está claro que en este contexto una oración de entrada no es una observación, sino una creencia para la que se busca una explicación (“La abducción", 133).

De otro lado, M.G. Navarro puntualiza que las hipótesis que derivan de la abducción son más interpretativas que explicativas ("Claves para la actualidad" 284-286)" . Esto significa que las hipótesis abductivas no explican un estado de cosas, sino que lo interpretan. No se trata entonces de la mejor explicación, sino de la conjetura interpretativa más razonable o plausible en el contexto de un horizonte hermenéutico. Esta perspectiva utiliza la abducción como bisagra para conectar una ontología hermenéutica con una pragmática argumentativa, que pretende, en últimas, desmentir el modelo de verdad como correspondencia. ${ }^{13}$

Reitero que la diferencia entre una y otra perspectiva es sutil y se basa, asimismo, en la sutileza de una distinción analítica que puede resultar artificial entre explicación y justificación (Atienza, 2006). De acuerdo con ella, la explicación consiste en establecer una relación de causas y efectos para señalar el 'por qué de una situación. De una decisión judicial podría decirse que fue tomada porque el juez es un conservador recalcitrante o porque está comprometido con la garantía de justicia social. De eso se trata el 'por qué' explicativo de una decisión.

La justificación se refiere a la necesidad de proporcionar razones para considerar plausible o razonable una decisión. Es decir, el 'por qué justificativo implica un respaldo o compromiso inferencial menos aséptico o neutro que el de la

13 Para profundizar este punto, se puede ver los textos de Blanco $(2016 ; 2014)$. 
explicación. La diferencia, creo, se debe buscar en el alcance del 'por qué: ambos generan un compromiso, pero en distinto grado. Quien postula una inferencia justificativa se compromete con la generosidad de la conclusión, mientras que la inferencia explicativa produce un compromiso con la verdad de una correlación entre causas y consecuencias, o medios y fines. El uso del discurso y la posición del hablante define el propósito de la inferencia: justificar o explicar.

De allí que la diferencia sea más de grado que sustancial. Ello se puede apreciar con total claridad en la película. Algunas de las hipótesis abductivas de losjurados se presentan con un claro tinte explicativo y otras funcionan como conjeturas que apuntan a justificar una interpretación determinada. Otras tantas se mueven en el continuum que va de la explicación a la justificación, y viceversa. En consecuencia, las dos perspectivas sobre la abducción no representan una oposición, sino el énfasis en aspectos que pueden ser complementarios. Tal como sucede en Doce hombres en pugna, las explicaciones abductivas pueden estar al servicio, como razones contribuyentes, de la justificación de conjeturas interpretativas.

\section{Argumentación y emociones}

Hay dos cosas para resaltar antes de que se nos acabe la cinta de celuloide. En los momentos finales hay, al menos, dos episodios tensos. En el primero de ellos, el jurado 7 cambia su voto, pero se niega a justificar por qué antes votó 'culpable' y ahora vota 'inocente. Frente a esta actitud, el jurado 11 le lanza una pregunta y le exige el cumplimiento de sus deberes argumentativos "¿qué clase de hombre es?... Si quiere votar 'inocente' hágalo porque está convencido de que el acusado lo es, no porque está cansado de hablar". El jurado 11 reclama al 7 para que le diga quién le dio el derecho para jugar así con la vida de un hombre.

Esta escena pone de presente la relación que existe entre argumentación y justicia: la observancia de un código de buenas prácticas argumentativas o una ética argumentativa de mínimos (Bordes, 2011; Van Eemeren y Grootendorst, 2011). Algunos de esos mínimos ético-argumentativos son: i) el de justificar, siempre que sea requerido, un punto de vista y ii) saturar la argumentación, es decir, respaldar con razones cada posición, premisa o postura en juego. Ser 
justos o hacer justicia en ese escenario presupone cumplir con el deber de argumentar por convencimiento o corrección, no por estrategia o conveniencia, a favor o en contra de un veredicto. La cuestión crucial aquí es que la justicia, las controversias que se ventilan en los tribunales, requiere una retórica ética.

El segundo episodio tiene lugar después de que la duda ha destronado las últimas verdades y solo el jurado 3, el presidente, se obstina en el veredicto de culpable. Ante el cambio de opinión paulatino de los jurados restantes, el jurado 3 se deshizo en llanto y en medio de las lágrimas declaró al acusado "no culpable". Tal como lo reconoce, las razones para sostener su voto a favor de la condena obedecían a un profundo sentimiento de resentimiento hacia sus propios hijos, que pretendía sublimar, sin saberlo, mediante el castigo al joven sentado en el banquillo de los acusados. Esta escena ilustra el papel de las emociones en la argumentación, las cuales cumplen un papel cognitivo dado que están referidas a un objeto perceptual y condicionan nuestra aproximación al mundo. En tal medida constituyen un elemento fundamental dentro de cualquier cosmovisión. Las emociones son tan importantes como la argumentación razonable para actuar o tomar una decisión (Damasio, 2015 [1995]; Navarro, 2010).

No parece cierto que la argumentación racional ponga en suspenso las emociones. Todo lo contrario, estas son, quizás, el detonante de aquella y el fluido que recorre silencioso todo argumento. El error está en no precaverse de ello. De acuerdo con Nietzsche, el logos -discurso o lenguaje-

[...] ha debido recorrer toda la escala de sus posibilidades para abarcar el reino del pensamiento, es decir, de lo justamente opuesto al sentimiento, alejándose de esa forma de las fuertes manifestaciones del sentimiento [...]. Así la humanidad añade a todos sus dolores el sufrimiento de la convención, es decir, concordar en palabras y acciones, pero no en sentimientos (ctd. En Santiago Guervós, 34).

Hasta años recientes reconocemos que Nietzsche tenía razón: no podemos olvidar las emociones y los sentimientos cuando de argumentación se trata, por mayor esfuerzo que hagamos en ser por completo racionales. La dictadura de la razón está condenada al fracaso, aunque un gobierno racional abierto a la participación de las emociones puede lograr buenos resultados. Lo importante 
es no pasar de una dictadura a otra. En contra de Nietzsche, la retórica no es solo pathos o emociones sin contenido cognitivo.

\section{A modo de conclusión}

He intentado mostrar algunos debates que atraviesan las teorías de la argumentación contemporáneas, a partir de Doce hombres en pugna. En la primera parte del artículo se dio cuenta de tres discusiones. En primer lugar, el lugar del pathos, el logos y el ethos en la retórica, sobre lo cual se siguió la línea marcada por Meyer en el sentido en que no puede suprimirse ninguno de estos elementos en lo que se refiere a la retórica como disciplina y como ejercicio del discurso argumentativo. La dinámica entre esos elementos permite que los problemas se reabran y los procesos de persuasión se renueven. La retórica tiene lugar allí donde la duda aparece. Sin la duda no hay retórica o argumentación.

En segundo lugar, se hicieron algunas consideraciones acerca de la relación entre retórica y dialéctica. Esta relación no puede asumirse como una oposición radical o una incompatibilidad insuperable, sino que debe verse como una complementación entre dos dimensiones de la argumentación que difieren en algún grado, pero no en la esencia. En tercer lugar, se replicó la posición de Angenot sobre el fracaso de la persuasión como preocupación central de la retórica en el sentido de que si bien son más frecuentes los eventos en los que la persuasión fracasa, no por ello los fenómenos de persuasión deben ser desatendidos. El éxito de la persuasión es concomitante con su fracaso: se persuade a algunos y a otros no. Ambos merecen atención. Por demás, para la acción colectiva parece necesario algún tipo de persuasión entre los que actúan.

En la segunda parte del texto, se revisó el problema de la abducción a partir de tres dimensiones básicas. La inferencial, que se refiere a la estructura del razonamiento abductivo, el tipo y la fuerza de la conclusión que arroja. La abducción funciona como dispositivo argumentativo para generar dudas, no para resolverlas. Para resolver esas dudas se hace necesario otro tipo de recursos argumentativos. La dimensión metodológica señala un camino por explorar, más que el camino recorrido. Asimismo, la intuitiva se refiere a la generación no racional de hipótesis o conjeturas que deben ser confirmadas. 
Las tres dimensiones apuntan al mismo objetivo: mostrar cuál puede ser la solución o la mejor comprensión o la mejor explicación de un fenómeno nuevo o diferente. La película ofrece varios ejemplos que permiten ilustrar estas dimensiones de lo abductivo. La abducción permitió esbozar algunos criterios para comprender la distinción entre justificar y explicar, a partir de los distintos compromisos que se contraen con una explicación o una justificación, al responder a tipos diferentes de 'por qué'.

En la parte final del artículo, se dejó abierto un problema: la relación entre argumentación y emociones. Este último tópico no fue desarrollado del todo, sino que fue insinuado y se propusieron dos aspectos problemáticos: i) la relación entre ética y argumentación retórica que permite hacer frente a las objeciones que equiparán retórica y manipulación; y ii) el papel de las emociones en la argumentación racional: ¿emociones racionales? Una perspectiva que vale la pena explorar para obtener una mejor comprensión del problema que resulta pertinente en los contextos sociopolíticos recientes.

Doce hombres en pugna cumplió su función: abrir la ventana para aproximarnos a ciertas cuestiones de la teoría de la argumentación, como las que aquí hemos repasado. Quizás he omitido algunos temas relevantes y otros han merecido más y mejor desarrollo, pero el objetivo del artículo era servir de introducción a estos problemas, a los que vale la pena dedicarle investigaciones independientes, para que el lector interesado asuma la tarea de profundizarlos $\mathrm{o}$, al menos, vea un clásico del cine con un nuevo prisma.

\section{Referencias}

Aguayo, P. "La teoría de la abducción de Peirce: lógica, metodología e instinto”. Ideas $y$ Valores, 145(2011): 33-53.

Angenot, M. El discurso social. Los límites históricos de lo pensable y lo decible. Buenos Aires: Siglo XXI Editores, 2010.

Angenot, M. El retorno de la retórica. Recuperado de: https://es.scribd.com/ document/155747961/Marc-Angenot-El-retorno-de-la-retorica. 31, mayo, 2018.

Aliseda, A. "La abducción como cambio epistémico: C.S. Peirce y las teorías epistémicas en inteligencia artificial”. Analogía, 12, (1998): 125-144.

Aliseda, A. “Abductive Reasoning: Challenges Ahead”. Theoria, 60 (2007): 261-270. 
Aristóteles. Retórica. Madrid: Centro de Estudios Políticos y Constitucionales, 2003.

Atienza, M. El derecho como argumentación. Barcelona: Ariel, 2006.

Blanco C., D. El viaje de las razones. Hacia una pragmática de la ponderación. Bogotá: Editorial Ibáñez, 2016.

Blanco C., D. "Consideraciones sobre la verdad en el discurso normativo". Derecho Público, 33 (2014): 1-16.

Bonorino, P. “Sobre la abducción”. Doxa, 14, (1993): 207-241.

Bordes S., M. Las trampas de Circe: falacias lógicas y argumentación informal. Madrid: Ediciones Cátedra, 2011.

Brandom, R. La articulación de las razones. Una introducción al inferencialismo. Madrid: Siglo XXI Editores, 2002.

Constaín, J. P. "El pensamiento delirante". Periódico El Tiempo, 10 de agosto de 2016. Disponible https://www.eltiempo.com/opinion/columnistas/juanesteban-constain/el-pensamiento-delirante-juan-esteban-constain-columna-eltiempo-53940 10 jun. 2019.

Copi, I. y Cohen, C. Introducción a la lógica. México: Editorial Limusa, 2013.

Damasio, A. El error de Descartes. Barcelona: Editorial Planeta, 2015.

Hart, H.L.A. El concepto de derecho. Buenos Aires: Abeled-Perrot, 1995.

Kuhn, T. La estructura de las revoluciones científicas. México: Fondo de Cultura Económica, 2013.

Meyer, M. La rhetorique. Paris, puf, Que sais-je? Traducción libre de María Elena Bitonte. 2004. Disponible https://tallerlecturayescritura2unm.files.wordpress. com/2012/08/meyer-2004-trad-bitonte-zamudio.doc 10 jun.2019.

Meyer, M. Principia Rhetorica. Una teoría general de la argumentación. Buenos Aires: Amorrortu Editores, 2013.

Navarro, M.G. Claves para la actualidad de la hermenéutica. Madrid: UNED, 2007. Tesis Doctoral.

Navarro, M.G. "Dudas razonables, sesgos cognitivos y emociones en la argumentación jurídica. El caso de Doce hombres sin piedad”. Bajo Palabra, 5,II(2010): 203-214.

Nietzsche, F. [1872]. Escritos sobre retórica. Madrid: Editorial Trotta, 2000.

Lewiński, M. "Practical reasoning in argumentative polylogues". Revista Iberoamericana de Argumentación 8 (2014): 1-20.

Padura, L. Máscaras. Madrid: Tusquest Editores, 2011.

Perelman, C. y Olbrechts-Tyteca, L. Tratado de la argumentación. La nueva retórica. Madrid: Editorial Gredos, 2006.

Peirce, C. Deducción, Inducción e Hipótesis. Buenos Aires: Editorial Aguilar, 1970.

Peirce, C. Lección VII: Pragmatismo y abducción. Recuperado de: http://www.unav.es/ gep/HarvardLecturesPragmatism/HarvardLecturesPragmatism7.html. 31 mayo 2018.

Plantin, C. "Sin demostrar ni emocionar(se)". Marafioti, R y Santibañez Cristián (Coord.). Teoría de la argumentación, a 50 años de Perelman y Toulmin. Buenos Aires: Editorial Biblos, 2010. 
Santiago Guervós, L.E. "El poder de la palabra: Nietszche y la retórica”. En Nietszche, F. Escritos sobre retórica. Madrid: Trotta, 2000. 9-77.

Van Eemeren, F. y Grootendorst, R. Una teoría sistemática de la argumentación. La perspectiva pragmadialéctica. Buenos Aires: Editorial Biblos, 2011.

Van Eemeren, F. Maniobras estratégicas en el discurso argumentativo. Madrid: Plaza y Valdes, 2012.

Vega, L. y Olmos, P. Compendio de Lógica, Argumentación y Retórica. Madrid: Editorial Trotta, 2013.

Walton, D. "What is reasoning? What is an argument?". The Journal of Philosophy, LXXVII, 8 (1990): 399-419. 